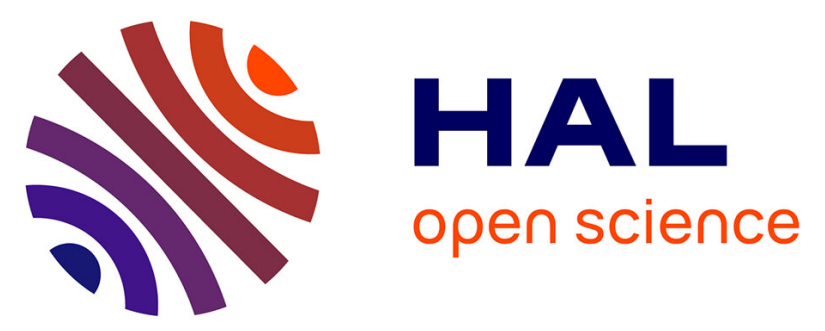

\title{
Comparing the effectiveness of peer instruction to individual learning during a chromatography course in a blended learning environment
}

Julien Morice, Nicolas Michinov, Marine Delaval, Alexandra Sideridou, Vincent Ferrières

\section{To cite this version:}

Julien Morice, Nicolas Michinov, Marine Delaval, Alexandra Sideridou, Vincent Ferrières. Comparing the effectiveness of peer instruction to individual learning during a chromatography course in a blended learning environment. Journal of Computer Assisted Learning, 2015, 31 (6), pp.722-733. 10.1111/jcal.12116 . hal-01224514

HAL Id: hal-01224514

https://hal-univ-rennes1.archives-ouvertes.fr/hal-01224514

Submitted on 14 Dec 2015

HAL is a multi-disciplinary open access archive for the deposit and dissemination of scientific research documents, whether they are published or not. The documents may come from teaching and research institutions in France or abroad, or from public or private research centers.
L'archive ouverte pluridisciplinaire HAL, est destinée au dépôt et à la diffusion de documents scientifiques de niveau recherche, publiés ou non, émanant des établissements d'enseignement et de recherche français ou étrangers, des laboratoires publics ou privés. 


\section{ACCEPTED ARTICLE (07/11/2015)}

If you plan to quote this manuscript, be sure to check the actual wording of the final published article

Morice J., Michinov N., Delaval M., Sideridou A., \& Ferrières V. (accepted). Comparing the effectiveness of Peer Instruction to individual learning during a chromatography course in a blended learning environment. Journal of Computer Assisted Learning. 


\title{
Comparing the effectiveness of Peer Instruction to Individual Learning during a chromatography course in a blended learning environment
}

\author{
Julien Morice $^{\text {1a }}$ \\ Nicolas Michinov * 2a \\ Marine Delaval ${ }^{2 a}$ \\ Alexandra Sideridou ${ }^{2 c}$ \\ Vincent Ferrières ${ }^{1 b}$
}

${ }^{\text {1a }}$ Ecole Nationale Supérieure de Chimie de Rennes

2a Université Rennes 2 (CRPCC, EA 1285)

${ }^{2 c}$ Université Rennes 2 (Histoire et critique des arts, EA 1279)

${ }^{1 b}$ Ecole Nationale Supérieure de Chimie de Rennes (CNRS UMR 6226)

* Corresponding author. Université Rennes 2 (CRPCC, EA 1285), Place du Recteur Henri Le Moal - CS 24307 - 35043 Rennes Cedex (France)

E-mail adresses: julienmorice@gmail.com,nicolas.michinov@univ-rennes2.fr, delaval.marine@gmail.com, al_sideridou@yahoo.fr , vincent.ferrieres@ensc-rennes.fr

This research was supported by the Maison des Sciences de l'Homme de Bretagne (Britanny, France). 


\begin{abstract}
Peer Instruction has been recognized as an instructional method having a positive impact on learning compared to traditional lectures in science courses. This method has been widely supported by the socio-constructivist approach to learning giving a positive role to interaction between peers in the construction of knowledge. As far as we know, no study has been conducted from the socio-cognitive approach which suggests that individuals working alone perform better than those interacting with others in groups. Thus, the aim of the present study was to examine whether Peer Instruction improves learning when compared with an Individual Learning method that does not require any interaction with peers. After being randomly divided into either a Peer Instruction or an Individual Learning condition for a practical session as part of a chromatography course, students could consult online resources to search for elements of response to a series of multiple-choice questions which they answered using clickers at the beginning (pre-test) and end of (post-test) the session. Results revealed no difference between the two conditions on learning gain, and showed that the percentage of correct answers increased similarly from the pre- to the post-test in both conditions. Nevertheless, students perceived the Peer Instruction method as being more satisfying, engaging, and useful than the Individual Learning method. Overall, the findings revealed that the Peer Instruction method provides subjective benefits compared to the Individual Learning method, but failed to demonstrate a greater learning gain when students could interact than when they could not.
\end{abstract}

Key words: Peer Instruction; Peer-learning; Individual Learning; Clickers; 


\section{Comparing the effectiveness of Peer Instruction to Individual Learning during a chromatography course in a blended learning environment}

\section{Introduction}

Currently, researchers and instructors are working to develop new instructional strategies to encourage students to engage actively in classroom activities to improve learning and academic performance (e.g., Freeman, Eddy, McDonough, Smith, Okoroafor, et al., 2014; Olapiriyakul \& Scher, 2006; Stephenson, Brown \& Griffin, 2008). A number of instructional strategies have been privileged to promote active learning through peer-to-peer interactions. Based on the socioconstructivist approach to learning which gives a crucial role to social interaction in the construction of knowledge, researchers have demonstrated that discussion and collaboration between peers have a positive impact on learning (e.g., Dillenbourg, Baker, Blaye \& O'Malley, 1996; Doise \& Mugny, 1984; Penuel, Abrahamson \& Roschelle, 2006; Vygotsky, 1978).

The present study used one of the most widely-known instructional methods based on the socio-constructivist approach, and popularized under the name of Peer Instruction (Crouch \& Mazur, 2001; Mazur, 1997). Its effectiveness has mainly been demonstrated by comparing it with the more traditional instruction method of lecturing. To our knowledge, no study has examined the effectiveness of the Peer Instruction method from a socio-cognitive approach when comparing its effects on learning to that of individuals working alone. According to this approach, in laboratory settings researchers have found that opportunities to interact with others may negatively influence performance of individuals in groups (e.g., Bond \& Smith, 1986; Latané, Williams \& Harkins, 1979; Mueller, 2012; Taylor, Berry \& Block, 1958). Consequently, the goal of the present study was to examine whether Peer Instruction improved learning when 
compared with an Individual Learning method which did not require any interaction with others, and was not simply a condition in which students attended a lecture. In other words, individual learning was extended beyond lecturing through a control condition where students were active in their learning but could not interact with their peers. After briefly describing the Peer Instruction method, and providing the main findings on learning obtained with this method from a socioconstructivist perspective, the interest of the alternative socio-cognitive approach of Peer Instruction to extend the empirical evidence of its effectiveness will be considered.

\section{The Peer Instruction method}

Peer Instruction is an interactive student-centred instructional strategy for engaging students during class through a structured questioning process that improves learning of fundamental sciences. The method was initially developed by the Harvard physicist Eric Mazur (1997) for a course entitled "Physics for Non-Majors". It aims to transform a course taught in a traditional lecture to a format that includes questions during the lecture, designed to actively engage students in discussions with their peers, and with students providing responses using remote answering devices or "clickers" also called "personal voting systems” or "audience response systems" (Crouch, Watkins, Fagen, \& Mazur, 2007; Crouch \& Mazur, 2001; Duncan, 2005; Mazur, 1997). These commercial or open-source hand-held systems convey students' responses to the teacher's questions (see Wikipedia, 2015). They enable students to answer questions asked in class with real-time, anonymous feedback, and also allow students to compare their performance with others, thus providing an incentive to exchange their ideas and solutions (e.g., Bank, 2006; Crouch \& Mazur, 2001; Fies \& Marshall, 2006; King \& Robinson, 2009; McDaniel, Agarwal, Huelser, McDermott, \& Roediger, 2011). Such electronic systems have been extensively used in many scientific disciplines (e.g., King \& Joshi, 2008; Landis, Ellis, Lisensky, Lorenz, Meeker, \& 
Wamser, 2001; MacArthur \& Jones, 2008), and a large number of studies have reported positive effects in learning contexts when clickers are used (e.g., Hinde \& Hunt, 2006; Kennedy \& Cutts, 2005; King \& Joshi, 2008; Knight \& Woods, 2005; Lucas, 2009; Martyn, 2007; Mayer et al., 2009; Purchase, Mitchell \& Ounis, 2004; Singh, 2005; Smith, Wood, Adams, Wieman, Knight et al., 2009). These positive effects have been attributed, at least in part, to the fact that clickers promote active learning and fruitful interactions between peers in the classroom (e.g., Anthony, 1996; Blasco-Arcas, Buil, Hernández-Ortega \& Javier Seze, 2013). Considering that such interaction between peers is a key component of active learning, the Peer Instruction method has been used to promote interactions between students, and to improve learning in a controlled way using clickers. Although different versions of the Peer Instruction method have been used, a typical sequence involves a series of steps and resembles a 'Think-Pair-Share' learning strategy (e.g., Lyman, 1981; Watkins \& Mazur, 2010), whereby students have to think individually about questions before sharing ideas and solutions with their classmates, either in pairs or in groups of three or four (see Footnote 1).

\section{The socio-constructivist approach to Peer Instruction}

Based on the socio-constructivist approach (e.g., Dillenbourg et al., 1996; Doise \& Mugny, 1984), giving a central role to social interaction in the construction of knowledge, the Peer Instruction method has been recognized for its positive impact on learning by encouraging students to interact with their peers instead of remaining passive during a lecture (e.g., Crouch \& Mazur, 2001; Crouch, Watkins, Fagen \& Mazur, 2007). The Peer Instruction method has mainly been demonstrated as being superior when compared to traditional methods, such as lectures attended by large numbers of students with no interaction (e.g., Hake, 1998; Mayer, Stull, DeLeeuw, Almeroth, Bimber et al., 2009). In contrast to traditional lectures, where the teacher's 
questions only elicit answers from the most motivated students, Peer Instruction is designed to involve all the students in the search for the solution, through discussion with peers. From this perspective, research has measured the method's learning gains, and has found that Peer Instruction not only makes students more active during lessons, but also stimulates learning, mainly by improving conceptual reasoning and problem-solving (Crouch et al., 2007). It has also been demonstrated that the proportion of correct answers supplied by students increases significantly after a period of peer discussion with their neighbours in the classroom (e.g., Hake, 1998), even if all the responses in the group were initially wrong (Singh, 2005; Smith et al., 2009). In a classical study aimed to measure the learning gains of 6,542 introductory students enrolled in interactive or traditional physics courses over a semester, Hake (1998) examined the results obtained on multiple-choice questions in a pre- and post-test to assess student understanding of the basic concepts of Newtonian physics. Recently, it has been clearly demonstrated that interactive courses yield higher learning gains than traditional courses in many science disciplines (see also Deslauriers, Schelew, \& Wieman, 2011; Freeman et al., 2014). As for other peer-to-peer instructional methods, the learning gains of Peer Instruction may result from the peer discussions during which students try to solve a cognitive conflict, testing and debating ideas of others to produce a better response than their own (e.g., Corden, 2001; Doise \& Mugny, 1984; Nicol \& Boyle, 2003; Weber, Maher, Powell \& Lee, 2008). Indeed, the cognitive conflict that arises from realizing that the views of others differ from one's own leads individuals to resolve their differences. This process may generate a deep understanding, and can include discussing in small groups which obliges students to consider a problem from different perspectives (e.g., Buchs, Pulfrey, Gabarrot, \& Butera, 2010; Springer, Stanne, \& Donovan, 1999). 
As previously mentioned, the majority of studies have compared the effectiveness of Peer Instruction with traditional lectures (e.g., Hake, 1998; Mayer et al., 2009). Recently, Freeman and collaborators (2014) claimed the importance of going beyond what they called 'the firstgeneration research', suggesting that "it is reasonable to raise concerns about the continued use of traditional lecturing as a control in future experiments. Instead, it may be more productive to focus on what we call 'second-generation research': using advances in educational psychology and cognitive science to inspire changes in course design" (Freeman et al., 2014, p. 8413).

From this perspective, up to now a few studies have examined Peer Instruction in a sociocognitive approach.

\section{The socio-cognitive approach to Peer Instruction}

Based on the socio-cognitive view of group functioning, a number of studies have demonstrated that group work may have a detrimental impact on performance compared to individuals working alone on a great variety of tasks from idea-generation to problem solving (e.g., Bond \& Smith, 1986; Latané, Williams \& Harkins, 1979; Mueller, 2012; Taylor, Berry \& Block, 1958). For example, it has been shown that when the contributions of each group member are combined into the final group product (such as for additive tasks), individual effort in the group decreases, and the group fails (e.g., Latané et al., 1979; Steiner, 1972; Taylor et al., 1958). This effect is greatly influenced by group size, with individuals in larger groups exerting less effort (e.g., Latané et al., 1979; Mueller, 2012), assuming less responsibility for the tasks (e.g., Wicker \& Mehler, 1971), and performing less well than individuals in small groups (e.g., Liden, Wayne, Jaworski \& Bennett, 2004). Moreover, individuals in groups may also fail in tasks for which the solution is difficult to demonstrate to others (e.g., Lorge \& Solomon, 1955; Laughlin, 1980; Laughlin \& Ellis, 1986; Steiner, 1972), and groups rarely perform better than their highest achieving 
members on such tasks (e.g., Hill, 1982; Laughlin, Bonner \& Miner, 2002). Generally, individuals in groups are also greatly influenced by their group members (e.g., Asch, 1951; Brooks \& Koretsky, 2011; Lucas, 2009), and comparison with less performing members within groups may contribute to reducing performance because of a "downward matching" process consisting in assimilating oneself to those lower performers (e.g., Paulus \& Dzindolet, 1993), or because less-prepared students may feel anxious about participating in the group, fearing they might be negatively evaluated by their peers (Micari \& Pazos, 2014).

As research based on the socio-cognitive approach has demonstrated that working alone often yields better results than working in groups, it is important that the Peer Instruction method should be compared to a control condition in which students have to work individually without interacting with their peers, but using clicker devices for both conditions. Paradoxically, very few studies have compared these two conditions over the same time period in a controlled way. The exception is a recent study which demonstrated benefits of knowledge transfer for Peer Instruction compared to individualized learning (Jones, Antonenko, \& Greenwood, 2012). Although this study revealed improved knowledge transfer in the Peer Instruction condition, the learning gain benefits of engaging in peer discussions were not demonstrated from a pre- to a post-test. Consequently, it is necessary to go further by comparing the learning gain among students randomly arranged in small groups and who can interact (Peer Instruction condition) with students who have no opportunity to interact (Individual Learning condition). This comparison is important because many studies revealed that peer-to-peer interactions and collaboration lead to better learning outcomes compared to individual learning (e.g., Johnson \& Johnson, 2008; Lou, Abrami, \& d'Appolonia, 2001; Perlmutter, Behrend, Kuo, \& Muller, 1989). 
Beyond testing the differences between these two instructional methods, the aim of the present study was to confront socio-constructivist and socio-cognitive approaches of learning. Depending on the theoretical approach adopted, two alternative hypotheses may be formulated. According to the socio-constructivist approach, a higher learning gain would be expected in the Peer Instruction condition than in the Individual Learning condition. On the other hand, according to the socio-cognitive approach, the learning gain should be higher in the Individual Learning condition than in the Peer Instruction condition.

\section{Method}

\section{Participants}

Participants were 50 chemical engineering students (27 women and 23 men) aged 19-24 years ( $M$ $=20, S D=0.88$ ) at a chemical engineering school. None of them had previously used a clickerbased system in their curriculum, or had experienced a Peer Instruction method.

\section{Material}

The experimental equipment consisted of a set of clickers and a receiver connected to a computer which, in turn, was linked to a video projector. A single software package (CPS Pulse, einstruction ${ }^{\circledR}$ by Turning technologies) enabled teachers to create and administer interactive PowerPoint ${ }^{\circledR}$ multiple-choice questions, and view participation rates and results in real time. More importantly, it provided the students with feedback on their responses in the form of a histogram displayed on the screen at the front of the classroom after all students had responded. The data could be exported in the form of a spreadsheet for further statistical analysis. 


\section{Procedure}

The procedure was organized within a twelve-hour blended-learning (or hybrid learning) course combining study of accessible online resources through PowerPoint ${ }^{\circledR}$ sound-slide presentations (8 hours of self-training divided into two four-hour sessions) and lectures (2 hours divided into two one-hour lectures) scheduled during one semester. The course ended with a two-hour experimental session using clickers during practical work at the end of the semester. This practical session was presented as a formative assessment, offering students the opportunity to test themselves though quizzes and to potentially improve their knowledge in chromatography (see Figure 1 for an overview of the blended learning course). In order to encourage the students to be fully involved in the session, they were informed that the questions delivered during the practical work session would be helpful for self-evaluation before the exam.

At the start of the academic year, and before being randomly divided into two distinctive conditions for the experimental session by a coin toss, all the students had to study online resources individually and attend lectures on chromatography given by the same teacher.

The clicker-based learning session took place at the end of the semester in a classroom equipped with 30 computers connected to the Internet. The teacher and a technical assistant divided equal numbers of students randomly into one of the two sessions for a lesson of chromatography. The first session represented the control condition with no interaction between students (Individual Learning), while the second session was used as the experimental condition with interaction between peers in groups of four (Peer Instruction). These sessions took place immediately after each other in the same classroom to avoid communication between students from the different groups. 
On arrival, each student was seated at a designated place in the computer lab according to the first letter of their surname, indicated by a name slip on each table. The teacher informed the students that they had been divided up for practical reasons due to a limited number of clickers and computers. In both conditions, students sat at tables equipped with PC computers facing the screen and the teacher's desk so that no student had their back to the teacher. For each condition, the students were given clickers. They were told that they would use them to answer a quiz during the practical session which aimed to give them formative feedback on their knowledge in chromatography learned during previous lectures and from online resources. The quiz consisted of a succession of 14 multiple-choice questions on chromatography. The questions were chosen from a database containing a large number of questions with several alternative responses for each. All the questions and their three or four associated alternative answers were validated by a pedagogical team. The correct answers were not directly available in the course notes or online resources, and required to be thought out either through calculation or reasoning (see Appendix for some sample questions). The researchers also participated in the validation process, agreeing on the validity of the questions chosen and the different responses. In the study, the questions were randomly sorted, and the order of presentation remained the same for all students and conditions. The teacher, who was also one of the authors of the present study, presented the questions on the screen one after the other and the students answered each using their clicker by choosing their response from the three or four options of which only one was correct.

\section{$<$ Insert Figure 1 >}

After a short training session using a few general knowledge questions aimed to teach students how to use clickers, the experimental session was organized around four successive stages during two hours of practical work: 
1. Depending on the difficulty of the questions, students were given between one and five minutes to answer a question individually using their clicker without discussion with their peers.

2. The students were then provided with collective feedback, displayed on the screen at the front of the class in the form of a histogram indicating the percentage of students who had selected each option. At this stage, the correct answers were not given.

3. Before answering the same questions a second time using their clickers, the students worked either individually or in four-member groups. Those in the Peer Instruction condition were instructed to think about each question and discuss it in randomly formed groups of four, while those in the Individual Learning condition were told to think about it entirely on their own. At this stage, the teacher did not communicate with students, and made sure that in the Individual Learning condition there was no communication between peers. To create equivalent conditions in terms of availability of pedagogical resources, all the students of the two learning conditions had full access to Internet. They were encouraged to explore their course notes and online resources, but because student behaviour was not recorded, such data were not quantified. The correct answers were not directly available in the course notes or online resources. The amount of time allowed for this individual or interactive work varied between one and five minutes per question depending on its difficulty.

4. Once all the participants had answered each question a second time, its correct answer was displayed on the screen, and the class discussed it with their teacher for different lengths of time (mean duration: 3 minutes), depending on the number of questions asked and the amount of information provided by the teacher. 
Immediately after the clicker-based learning session, the students were asked to answer an online three-item questionnaire to assess their perception of the learning method.

\section{Results}

All statistical analyses were performed using SPSS 20.0. A 2 (Learning method, Peer Instruction versus Individual Learning) $\times 2$ (Test of knowledge from quizzes, at the beginning and at the end of the session) between-within analysis of covariance (ANCOVA) was performed to determine whether students’ performance on the quiz using clickers improved differently from the beginning to the end of the session according to the learning method. In this analysis, test of knowledge was treated as a repeated measure, whereas learning method was considered as a between-subjects factor. The sex of participants was treated as a covariate because of its potential impact on performance (e.g., Jones et al., 2012; King \& Joshi, 2008; Lorenzo et al., 2006).

\section{Performance on the quiz}

In order to examine whether the Peer Instruction method gave better results than the Individual Learning method, the percentage of correct answers on the first and second quizzes were compared according to the experimental condition. This percentage was calculated for each student by dividing the sum of correct scores by 14 and multiplying by 100 . Learning gain was quantified by comparing the students' answers to the same 14-question taken before (first quiz/pre-test) and after the Peer Instruction or the Individual Learning session (second quiz/posttest). The percentage of correct answers on the first quiz varied from $21.43 \%$ to $78.57 \%$ and was normally distributed as revealed by the Kolmogorov-Smirnov goodness-of-fit (K-S Z=1.22, ns). The percentage of correct answers on the second quiz varied from $42.86 \%$ to $85.71 \%$ and was also normally distributed (K-S Z= 1.45, ns). 
The ANCOVA revealed that there was no sex or interaction effects (both $F s<1.0$ ), and that two main effects could be observed. The first within-factor effect revealed that the proportion of correct answers significantly increased from the first to the second quiz, $F(1,47)=59.25$, $p<.001, \eta^{2}=.56$. The second significant main effect showed that the percentage of correct answers was higher in the Peer Instruction condition than in the Individual Learning condition, $F(1,47)=$ 3.95, $p<.05, \eta^{2}=.08$. As can be seen in Figure 2, the former effect demonstrated a learning gain from the first to the second quiz, where the percentage of correct responses increased independently of the learning method. The latter effect only revealed that students were better in the Peer Instruction condition than in the Individual Learning condition, independently of the moment the quizzes were administered, suggesting that despite having been divided up randomly the students in the two conditions differed in their knowledge.

$<$ Insert Figure 2 about here >

\section{Perception of the learning method}

Students had to evaluate the usefulness of the learning method they had experienced, the degree to which it encouraged them to take part in class, and their overall satisfaction with the clickerbased learning session on a 4-point Likert scale ranging from 1 (Not at all useful/engaging/satisfying) to 4 (Really useful/engaging/satisfying).

As only main effects of the learning method on these measures were tested, a series of Student $t$-tests were performed on each dependent variable. The results showed that the students in the Peer Instruction condition found the learning method they had experienced more useful than those in the Individual Learning condition, $t(48)=2.48, p=.016$. They also felt the Peer Instruction method encouraged them to take part more in class, $t(48)=2.15, p=.017$. Furthermore, students in the Peer Instruction condition tended to express more overall 
satisfaction than those in the Individual Learning condition, $t(48)=1.80, p=.078$ (see Table 1 ).

$<$ Insert Table 1 here $>$

\section{Discussion}

The aim of the present study was to examine whether Peer Instruction improves learning when compared with an Individual Learning method that does not require any interaction with peers. This comparison is important because a large body of studies based on the socio-cognitive approach has revealed that working in groups may have a detrimental impact on performance compared to individuals working alone (e.g., Asch, 1951; Hill, 1982; Taylor et al., 1958; Steiner, 1972; Latané et al., 1979), and this difference is mainly due to socio-cognitive processes negatively affecting performance in groups (e.g., conformity, evaluation apprehension, social loafing, social comparison). This perspective greatly contrasts with the socio-constructivist approach which generally supports Peer Instruction research, and gives a positive role to social interaction in the construction of knowledge. However, the effectiveness of the Peer Instruction method has essentially been demonstrated by comparing it with the more traditional instructional method of lecturing. It is therefore difficult to verify that improved learning gain is solely due to students benefiting from interactions with their peers compared to students performing the same task without any interaction. In the present study, depending on these two distinctive theoretical approaches, alternative hypotheses were formulated. The first, based on the socio-constructivist approach, predicted a higher learning gain in the Peer Instruction condition than in the Individual Learning condition. The second, based on the socio-cognitive approach, predicted a higher learning gain in the Individual Learning condition than in the Peer Instruction condition.

Contrary to each of these predictions, the findings revealed a lack of difference between 
the two conditions with students in the Peer Instruction condition obtaining a similar learning performance to those in the Individual Learning condition. Consequently, neither of the two alternative hypotheses based on either socio-constructivist or socio-cognitive approach are supported. Indeed, the present study failed to demonstrate that Peer Instruction improved the proportion of correct answers from the first to the second quiz more than for Individual Learning (socio-constructivist hypothesis). It also failed to demonstrate the reverse effect that Individual Learning produced more correct answers than Peer Instruction (socio-cognitive hypothesis). However, although students in the Peer Instruction condition did not achieve better learning performance on quizzes than those in the Individual Learning condition, they rated the usefulness of the Peer Instruction method more highly, expressed greater satisfaction, and felt that this method encouraged them to take part in class (see also Martyn, 2007). In other words, when students can interact with each other to share their ideas and solutions for their responses to quizzes, they are more engaged and satisfied than when they cannot, but they do not learn more deeply with peer interaction than without it . Although these findings may appear surprising with regard to the literature which demonstrates the effectiveness of Peer Instruction on learning gain, they also contribute to introducing new perspectives in this field. The lack of difference on learning gain between the conditions may be explained by a similar engagement of students in both conditions in which they actively worked on the chromatography questions instead of remaining passive as in traditional lectures. It is reasonable to assume that the blended learning environment may explain, at least in part, the present findings. Indeed, because all the students had an access to online resources to help find the right answers to quizzes, those in the Peer Instruction condition may have learned actively from these resources in the same way as students in the Individual Learning condition rather than collaboratively from interaction with their peers. 
The present results also contrast with recent findings demonstrating the superiority of Peer Instruction on knowledge transfer compared to individualized responses using clickers (Jones et al., 2012). However, as previously indicated, this latter study did not examined the learning gain between the two instructional methods, and online resources were not accessible during the course. From this perspective, the present study goes beyond previous research in the field integrating the comparison of instructional methods in a blended learning environment in which online resources are accessible both for prior self-study and during the clicker-based learning session itself.

\section{Conclusion, limitations, and perspectives}

This study set out to compare the learning gain under two conditions, one in which students interacted with their peers (Peer Instruction) and the other in which there was no student interaction (Individual Learning). Beyond the traditional instructional method where students "passively" attend lectures, the two learning methods used in the present study may be considered as “active” because students were tested in a classroom equipped with computers to access online resources and where clicker devices could be used to stimulate student engagement with course content. Despite the practical advantages of the present results for instructional design in the classroom, the theoretical findings are more nuanced because they do not support either the socio-constructivist approach or the socio-cognitive approach. On the one hand, and contrary to predictions based on the socio-constructivist approach, the present study demonstrated that Peer Instruction did not produce a greater learning gain than Individual Learning. On the other hand, and contrary to predictions based on the socio-cognitive approach, the Individual Learning method failed to result in better learning gain from the pre-test to the post-test compared to Peer 
Instruction. The fact that working alone produces the same learning gain as interacting with peers, at least when the Peer Instruction method is used, suggests some limitations of the systematic superiority of Peer Instruction observed when the latter was compared to traditional lectures.

As such, this study may be considered as an attempt to shift from 'first-generation research' (active learning vs. traditional lectures as control condition) to 'second-generation research' (see Freeman et al., 2014). In terms of the latter, the present research opens up new perspectives for questioning the systematic superiority of Peer Instruction over other individual learning methods, at least in blended learning environments. In the future, 'second-generation research' should be developed further through a series of experiments aiming to investigate the effectiveness of Peer Instruction compared to other collaborative and/or active learning methods.

At least three limitations may be identified in the present study. Firstly, the sample used in the present study was small, and despite the randomization procedure allowing the hypotheses to be tested, further research should incorporate a greater number of students to examine the potential impact of moderating variables such as sex differences which have been recognized as being important in some previous studies (e.g., Jones et al., 2012; King \& Joshi, 2008; Lorenzo et al., 2006). Secondly, all students in the present study had the opportunity to consult online resources during the course, and this strategy may have limited the benefits of social interactions on learning gain often observed in the Peer Instruction literature. It would be interesting in future research in this field to orthogonalize two variables, instructional strategy (Individualized vs. Peer Instruction) and availability of online resources to answer quizzes (with vs. without resources) to be able to distinguish 'collaborative learning' from 'active learning'. Finally, the group size was controlled in the present study and all the groups had four members. Group size 
should systematically be controlled when Peer Instruction takes place because of the importance of this variable in the socio-cognitive approach. Indeed, a number of studies have shown a social loafing effect with individuals in larger groups exerting less effort and responsibility for the tasks, and performing less well than individuals in small groups (e.g., Liden et al., 2004; Mueller, 2012; Wicker \& Mehler, 1971). For this reason future studies should rigorously control group size from two, including proximate neighbours in the classroom, to four members, as was the case in the present study. The learning benefits generally observed in Peer Instruction literature could be due to the fact that students interacted only with one or two peers often seated beside them in the classroom. This small group or dyad situation may have potentially contributed to preventing social loafing, and to improving learning performance under the Peer Instruction condition.

Finally, we hope that this study will invite educational researchers and teachers to introduce changes in their course design taking into account both socio-constructivist and sociocognitive approaches. Far from sufficient in itself, the present study requires further research to examine in more detail the advantages and limitations of Peer Instruction as an effective instructional strategy to improve learning.

\section{Footnotes}

${ }^{1}$ A Peer Instruction session is usually structured as follows: (1) before a lesson, students familiarize themselves with the various pedagogical (online) resources available to them (course material, written documents, sound-slide presentations, videos, etc.); (2) the lesson is divided into different sections, each focusing on a key concept that the teacher explains before asking the students to answer multiple-choice questions individually using clickers; (3) the students discuss their answers with their peers, generally students who are seated beside them, before responding to the same questions a second time; (4) The sequence ends by a discussion with the whole class. 


\section{References}

Anthony, G. (1996). Active learning in a constructivist framework. Educational Studies in Mathematics, 31, 349-369. doi:10.1007/BF00369153

Asch, S. E. (1951). Effects of group pressure on the modification and distortion of judgements. In H. Guetzkow (Ed.), Groups, leadership and men (pp. 177-190). Pittsburgh, PA: Carnegie Press.

Banks, D. (2006). Audience response systems in higher education: Applications and cases. Hershey, PA: Information Science Publishing.

Blasco-Arcas, L., Buil, I., Hernández-Ortega, B., \& Javier Seze, F. (2013). Using clickers in class. The role of interactivity, active collaborative learning and engagement in learning performance. Computers and Education, 62, 102-110. doi:10.1016/j.compedu.2012.10.019

Bond, R., \& Smith, P. B. (1996). Culture and conformity: A meta-analysis of studies using Asch’s (1952b, 1956) line judgment task. Psychological Bulletin, 119, 111-137.doi: 10.1037/00332909.119.1.111

Brooks, B. J., \& Koretsky, M. D. (2011). The influence of group discussion on students’ responses and confidence during Peer Instruction. Journal of Chemical Education, 88 (11), 1477-1484. doi: 10.1021/ed101066x

Buchs, C., Pulfrey, C., Gabarrot, F., \& Butera, F. (2010). Competitive conflict regulation and informational dependence in peer learning. European Journal of Social Psychology, 40, 418-435. doi:10.1002/ejsp.631

Corden, R.E. (2001). Group discussion and the importance of a shared perspective: Learning from collaborative research. Qualitative Research, 1 (3), 347-367.

doi:10.1177/146879410100100305 
Crouch, C. H., \& Mazur, E. (2001). Peer Instruction: Ten years of experience and results. American Journal of Physics, 69 (9), 970-977. doi:10.1119/1.1374249

Crouch, C. H., Watkins, J., Fagen, A. P., \& Mazur, E. (2007). Peer Instruction: Engaging students one-on-one, all at once. Reviews in Physics Education Research, 1(1), 40-95.

Deslauriers, L., Schelew, E., \& Wieman, C. (2011). Improved learning in a large-enrollment physics class. Science, 332, 862-864. doi: 10.1126/science.1201783

Dillenbourg, P., Baker, M., Blaye, A., \& O'Malley, C. (1996). The evolution of research on collaborative learning. Learning in Humans and Machine: Towards an interdisciplinary learning science (pp. 189-211). Oxford: Elsevier.

Doise, W., \& Mugny, G. (1984). The social development of the intellect. Oxford: Pergamon Press.

Duncan, D. (2005). Clickers in the classroom: How to enhance science teaching using classroom response systems. San Francisco: Pearson Education.

Fies, C., \& Marshall, J. (2006). Classroom response systems: A review of the literature. Journal of Science Education and Technology, 15, 101-109. doi: 10.1007/s10956-006-0360-1

Freeman, S., Eddy, S., McDonough, M., Smith, M. K., Okoroafor, N., Jordt, H., \& Wenderoth, M. (2014). Active learning increases student performance in science, engineering and mathematics. Proceedings of the National Academy of Sciences, 111 (23), 8410-8415. doi: 10.1073/pnas.1319030111

Hake, R. (1998). Interactive engagement versus traditional methods: A six-thousand student survey of mechanics test data for introductory physics courses. American Journal of Physics, 66 (1), 64-74. doi: 10.1119/1.18809 
Hill, G.W. (1982). Group versus individual performance: Are N + 1 heads better than one? Psychological Bulletin, 91, 517-539. doi: 10.1037/0033-2909.91.3.517

Hinde, K., \& Hunt, A. (2006). Using the personal response systems to enhance student learning: Some evidence from teaching economics. In D. Banks (Ed.), Audience response systems in higher education: Applications and cases (pp. 140-154). Hershey, PA: Information Science Publishing. doi:10.4018/978-1-59140-947-2.ch010

Johnson, D., \& Johnson, R. (2008). Cooperation and the use of technology. In J. M. Spector, M. D. Merrill, J. van Merrienboer, \& M. Driscoll (Eds.), Handbook of research on educational communications and technology (3rd ed., pp. 1017-1044). New York, NY: Taylor \& Francis.

Jones, M.E., Antonenko, P.D., \& Greenwood, C.M. (2012). The impact of collaborative and individualized student response system strategies on learner motivation, metacognition, and knowledge transfer. Journal of Computer Assisted Learning, 28 (5), 477-487. doi:

10.1111/j.1365-2729.2011.00470.x

Kennedy, G. E., \& Cutts, Q. I. (2005). The association between students' use of an electronic voting system and their learning outcomes. Journal of Computer Assisted Learning, 21, 260268. doi:10.1111/j.1365-2729.2005.00133.x

King, D. B., \& Joshi, S. (2008). Gender differences in the use and effectiveness of personal response devices. Journal of Science Education and Technology, 17(6), 544-552. doi:10.1007/s10956-008-9121-7

King, S. O., \& Robinson, C. L. (2009). Staff perspectives on the use of technology for enabling formative assessment and automated student feedback. Italics, 8(2), 24-35.

Knight, J. K., \& Wood, W. B. (2005). Teaching more by lecturing less. Cell Biology Education, 4, 298-310. doi: 10.1187/05-06-0082. 
Landis, C.R., Ellis, A.B., Lisensky, G.C., Lorenz, J.K., Meeker, K., \& Wamser, C.C. (2001).

Chemistry ConcepTests: A pathway to interactive classrooms. San Francisco: Prentice-Hall.

Lantz, M. E. (2010). The use of “Clickers” in the classroom: Teaching innovation or merely an amusing novelty? Computers in Human Behavior, 26 (4), 556-561.

doi:10.1016/j.chb.2010.02.014

Latané, B., Williams, K., \& Harkins, S. (1979). Many hands make light the work: The causes and consequences of social loafing, Journal of Personality and Social Psychology, 37, 822-832. doi:10.1037/0022-3514.37.6.822

Laughlin, P. R. (1980). Social combination processes of cooperative problem solving groups on verbal intellective tasks. In M. Fishbein (Ed.), Progress in social psychology (pp. 127-155). Hillsdale, NJ: LEA.

Laughlin, P. R., Bonner, B. L., \& Miner, A. G. (2002). Groups perform better than the best individuals on letters-to-numbers problems. Organizational Behavior and Human Decision Processes, 88, 605-620. doi:10.1016/S0749-5978(02)00003-1

Laughlin, P. R., \& Ellis, A. L. (1986). Demonstrability and social combination processes on mathematical intellective tasks. Journal of Experimental Social Psychology, 22, 177-189. doi:10.1016/0022-1031(86)90022-3

Liden, R.C., Wayne, S.J., Jaworski, R.A., \& Bennett, N. (2004). Social loafing: A field investigation. Journal of Management, 30, 285-304. doi: 10.1016/j.jm.2003.02.002

Lorge, I., \& Solomon, H. (1955). Two models of group behavior in the solution of eureka-type problems. Psychometrica, 20, 139-148. doi:10.1007/BF02288986

Lorenzo, M., Crouch, C.H., \& Mazur, E. (2006). Reducing the gender gap in the physics classroom. American Journal of Physics, 74 (2), 118-122. doi:10.1119/1.2162549 
Lou, Y., Abrami, P., \& d'Appolonia, S. (2001). Small group and individual learning with technology: A meta-analysis. Review of Educational Research, 71, 449-521. doi: $10.3102 / 00346543071003449$

Lucas, A. (2009). Using Peer Instruction and i-clickers to enhance student participation in calculus. PRIMUS, 19(3), 219-231. doi:10.1080/10511970701643970

Lyman, F. T. (1981). The responsive classroom discussion: The inclusion of all students. In A. Anderson (Eds.), Mainstreaming Digest (pp. 109-113). College Park: University of Maryland Press.

MacArthur, J. R., \& Jones, L.L. (2008). A review of literature reports of clickers applicable to college chemistry classrooms. Chemistry Education Research and Practice, 9, 187-195. doi:10.1039/b812407h

Martyn, M.(2007). Clickers in the classroom: An active learning approach. EDUCAUSE, 30, 7174.

Mayer, R. E., Stull, A., DeLeeuw, K., Almeroth, K., Bimber, B., Chun, D., Bulger, M., Campbell, J., Knight, A., \& Zhang, H. (2009). Clickers in college classrooms: Fostering learning with questioning methods in large lecture classes. Contemporary Educational Psychology, 34(1), 51-57. doi: 10.1016/j.cedpsych.2008.04.002

Mazur, E. (1997). Peer Instruction: A user's manual series in educational innovation. Upper Saddle River, NJ: Prentice Hall.

McDaniel, M. A., Agarwal, P. K., Huelser, B. J., McDermott, K. B., \& Roediger, H. L. (2011). Test-enhanced learning in a middle school science classroom: The effects of quiz frequency and placement. Journal of Educational Psychology, 103, 399-414. doi: 10.1037/a0021782

Micari, M., \& Pazos, P. (2014). Worrying about what others think: A social-comparison concern 
intervention in small learning groups. Active Learning in Higher Education, 15 (3), 249-262. doi: $10.1177 / 1469787414544874$

Moss, K., \& Crowley, M. (2011). Effective learning in science: The use of personal response systems with a wide range of audiences. Computers and Education, 56, 36-43. doi:10.1016/j.compedu.2010.03.021

Mueller, J.S. (2012). Why individuals in larger teams perform worse. Organizational Behavior and Human Decision Processes, 117, 111-124. doi : 10.1016/j.obhdp.2011.08.004.

Nicol, D. J., \& Boyle, J. (2003). Peer instruction versus class-wide discussion in large classes: A comparison of two interaction methods in the wired classroom. Studies in Higher Education, 28(4), 458-473. doi:10.1080/0307507032000122297

Olapiriyakul, K., \& Scher, J. (2006). A guide to establishing hybrid learning courses: Employing information technology to create a new learning experience, and a case study. (The) Internet and Higher Education, 9, 287-301. doi:10.1016/j.iheduc.2006.08.001

Paulus, P. B., \& Dzindolet, M. T. (1993). Social influence processes in group brainstorming. Journal of Personality and Social Psychology, 64, 575-586. doi:10.1037//00223514.64.4.575.

Penuel, W. R., Abrahamson, L., \& Roschelle, J. (2006). Theorizing the transformed classroom sociocultural interpretation of the effects of audience response systems in higher education. In D. Banks (Ed.), Audience response systems in higher education: Applications and cases (pp. 187-208). Hershey, PA: Information Science Publishing. doi: 10.4018/978-1-59140947-2.ch013

Perlmutter, M., Behrend, S.D., Kuo, F., \& Muller, A. (1989). Social influences on children's problem solving. Developmental Psychology, 25, 744-754. doi:10.1037/0012- 
1649.25.5.744

Purchase, H., Mitchell, C., \& Ounis, I. (2004). Gauging students’ understanding through interactive lectures. Lecture Notes in Computer Science, 3112, 234-243. doi:10.1007/978-3540-27811-5_21

Singh, C. (2005). Impact of peer interaction on conceptual test performance. American Journal of Physics, 73, 446-451. doi:10.1119/1.1858450

Smith, M. K., Wood, W. B., Adams, W. K., Wieman, C., Knight, J. K., Guild, N., \& Su, T. T. (2009). Why peer discussion improves student performance on in-class concept questions. Science, 323, 122-124. doi: 10.1126/science.1165919

Springer, L., Stanne, M., \& Donovan, S. (1999). Effects of small-group learning on undergraduates in science, mathematics, engineering, and technology: A meta-analysis. Review of Educational Research 69 (1), 21-51. doi: 10.3102/00346543069001021

Steiner, I. D. (1972). Group processes and productivity. New York: Academic Press.

Stephenson, J., Brown, C., \& Griffin, D. (2008). Electronic delivery of lectures in the university environment: An empirical comparison of three delivery styles. Computers and Education, 50, 640-651. doi:10.1016/j.compedu.2006.08.007

Taylor, D. W., Berry, P. C., \& Block, C. H. (1958). Does group participation when using brainstorming facilitate or inhibit creative thinking? Administrative Science Quarterly, 6, 22-47. doi:10.2307/2390603

Vygotsky, L.S. (1978). Mind in society: The development of higher psychological processes. Cambridge, MA: Harvard University Press.

Watkins, J., \& Mazur, E., (2010). Just-in-Time Teaching and Peer Instruction, In S. Simkins \& M.H. Maier (Eds.), Just in Time Teaching: Across the disciplines, and across the academy 
(pp. 39-62). Sterling, VA: Stylus Publishing.

Weber, K., Maher, C., Powell, A., \& Lee, H.S. (2008). Learning opportunities from group discussions: Warrants become the objects of debate. Educational Studies in Mathematics, 68 (3), 247-261. doi:10.1007/s10649-008-9114-8

Wicker, A.W., \& Mehler, A. (1971). Assimilation of new members in a large and a small church. Journal of Applied Psychology, 55, 151-156. doi :10.1037/h0030705

Wikipedia (2015). Audience response. Retrieved January 16, 2015, from http://en.wikipedia.org/wiki/Audience_response 
Figure 1. Overview of the blended learning course in chromatography.

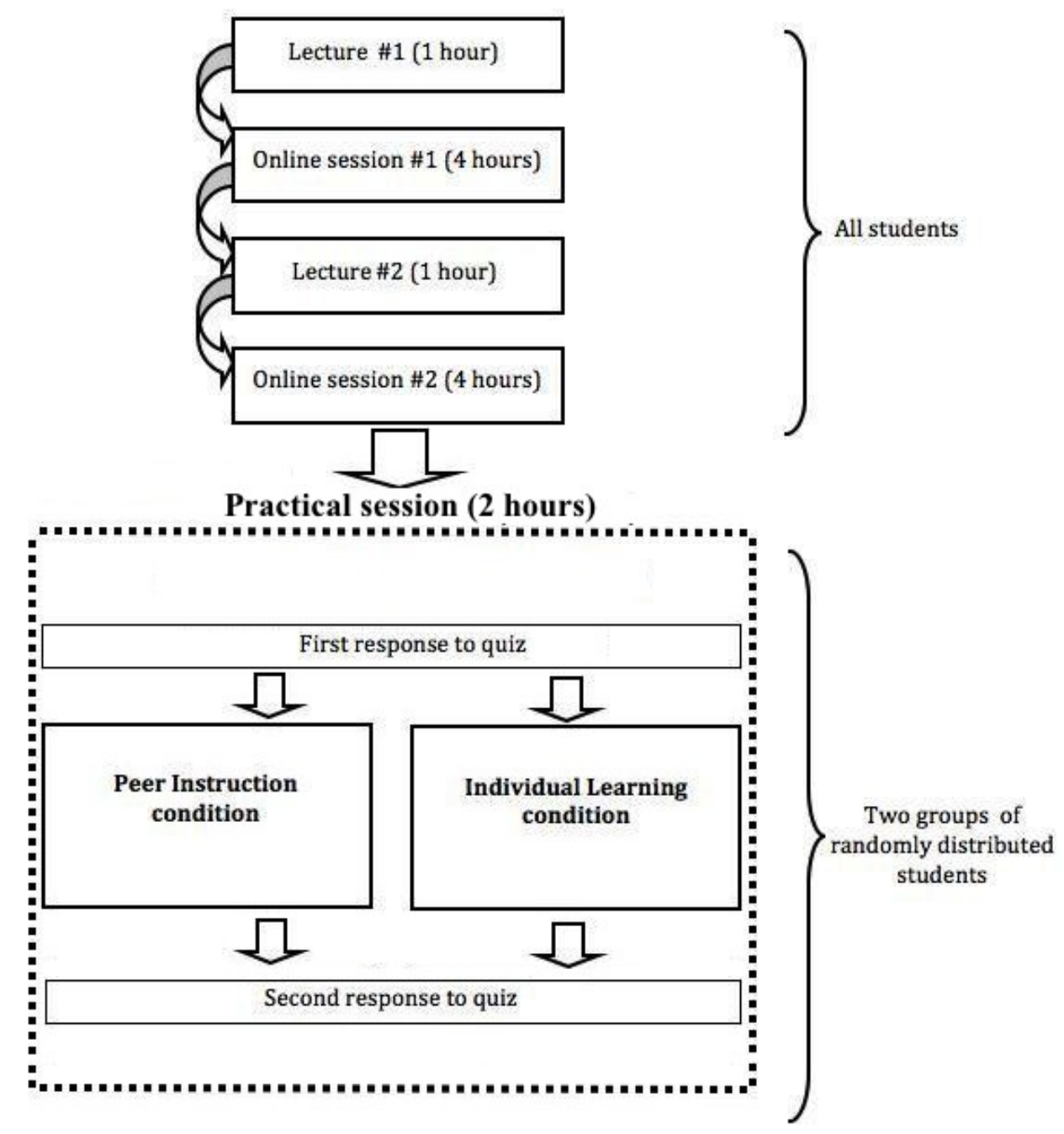


Figure 2. Effect of learning method (Peer Instruction or Individual Learning) and test of knowledge in chromatography (first and second quiz) on the percentage of correct responses.

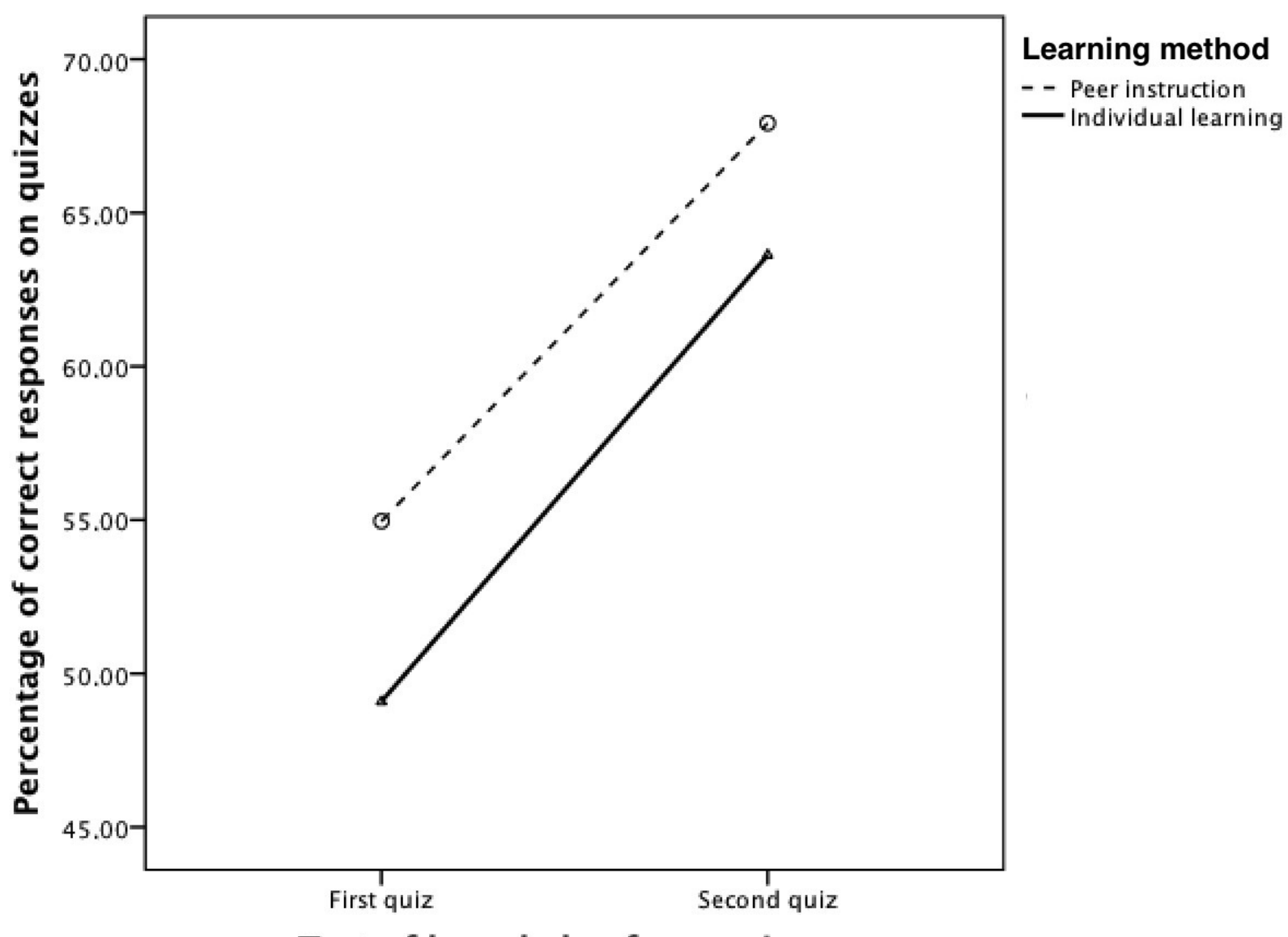

Test of knowledge from quizzes 


\section{APPENDIX}

Which chromatographic system would you recommend for analysing t-Butyl hydroxyanisole?
A. GC / Carbowax / hydrogen
B. HPLC / silica gel / dichloromethane-water
C. GC / nitrogen / reverse HPLC
D. HPLC / RP18 / dichloromethane-water

Rank the following alkanes in order of increasing boiling points:
A. n-pentane $<2$,2-dimethylpropane $<2$-methylbutane
B. n-pentane $<2$-methylbutane $<2$,2-dimethylpropane
C. 2,2-dimethylpropane $<2$-methylbutane $<$ n-pentane

In silica gel column chromatography, in which order would the following compounds be eluted?

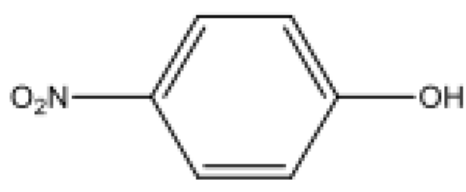

1

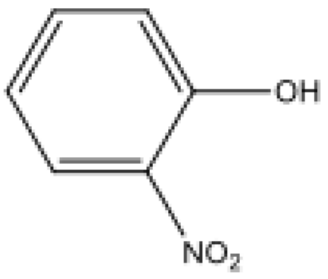

2

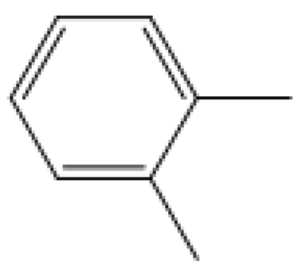

3

then 1 then 2

B. 3 then 2 then 1

C. 1 then 2 then 3

Using the chromatographic data shown in the table $(A=$ barbitone, $B=$ amobarbitone, $C=$ secobarbitone), calculate the response factors of amobarbitone and secobarbitone with respect to barbitone, and hence their amount in the test sample.

\begin{tabular}{|c|r|r|r|r|r|}
\hline $\begin{array}{c}\text { Retention } \\
\text { time (min) }\end{array}$ & $\begin{array}{c}\text { Area } \\
\text { (standard) }\end{array}$ & Area (\%) & $\begin{array}{c}\text { Retention } \\
\text { time (min) }\end{array}$ & Area (sample) & Area (\%) \\
\hline 0.26 & $7,335,600$ & 97.315 & 0.24 & $9,512,000$ & 98.186 \\
\hline 2.41 & 105,020 & 1.393 & 2.41 & 97,273 & 1.004 \\
\hline 4.91 & 54,984 & 0.729 & 4.49 & 39,295 & 0.406 \\
\hline 6.68 & 42,408 & 0.563 & 6.82 & 39,187 & 0.405 \\
\hline
\end{tabular}
A. $\mathrm{mB}=38.6 \mathrm{mg}, \mathrm{mC}=49.9 \mathrm{mg}$
B. $\mathrm{mB}=49.9 \mathrm{mg}, \mathrm{mC}=38.9 \mathrm{mg}$
C. $\mathrm{mB}=39.3 \mathrm{mg}, \mathrm{mC}=38.2 \mathrm{mg}$ 
Table 1. Mean ratings (M) and standard deviations (SD) of students'perceived utility, encouragement to participate, and satisfaction for each learning method.

\section{Learning method}

\begin{tabular}{|c|c|c|c|c|c|c|}
\hline \multirow{2}{*}{ Measures } & \multicolumn{2}{|c|}{ Peer Instruction } & \multicolumn{2}{|c|}{ Individual Learning } & \multirow[b]{2}{*}{ Significance ( $t$-tests) } & \multirow[b]{2}{*}{ Cohen's d } \\
\hline & $M$ & $S D$ & $M$ & $S D$ & & \\
\hline Perceived utility & 2.96 & 0.60 & 2.42 & 0.93 & $p=.016$ & 0.69 \\
\hline Overall satisfaction & 3.08 & 0.45 & 2.77 & 0.70 & $p=.078$ & 0.52 \\
\hline
\end{tabular}

Note. Higher scores indicate more positive assessments. 